BMJ Open

Ophthalmology

\title{
Acceptability of immediate sequential bilateral cataract surgery (ISBCS) in a public health care setting before and after COVID-19: a prospective patient questionnaire survey
}

\author{
Vishal Shah (D) , ${ }^{1}$ Khayam Naderi, ${ }^{1,2}$ Laura Maubon, ${ }^{1}$ Ashmal Jameel, ${ }^{1}$ \\ Darshak S Patel (D) , 'Jack Gormley, ${ }^{1}$ Sanjeev Heemraz, ${ }^{1}$ Elodie Azan, ${ }^{1}$ \\ Seema Verma, ${ }^{1}$ Sancy Low, ${ }^{1}$ David O'Brart ${ }^{1,2}$
}

To cite: Shah V, Naderi K, Maubon L, et al. Acceptability of immediate sequential bilateral cataract surgery (ISBCS) in a public health care setting before and after COVID-19: a prospective patient questionnaire survey. BMJ Open Ophthalmology 2020;5:e000554. doi:10.1136/ bmjophth-2020-000554

Received 29 June 2020 Revised 14 August 2020 Accepted 28 August 2020
(D) Check for updates

(c) Author(s) (or their employer(s)) 2020. Re-use permitted under CC BY-NC. No commercial re-use. See rights and permissions. Published by BMJ.

${ }^{1}$ Department of Ophthalmology, Guy's and St Thomas' NHS Foundation Trust, London, UK ${ }^{2}$ King's College London, London, UK

\section{Correspondence to} David 0'Brart; david.obrart@ gstt.nhs.uk

\section{ABSTRACT}

Objective To ascertain patient acceptance of immediate sequential bilateral cataract surgery (ISBCS) in the National Health Service (NHS).

Methods A survey was devised using a 5-point Likert scale for questions related to ISBCS, which patients undertook during their cataract outpatient appointment pre-COVID-19 lockdown and by telephone during the lockdown.

Results Questionnaires were completed for 267 patients. Most respondents were aged over 71 (51\%) and were female individuals (60\%). Forty-five per cent agreed/strongly agreed with opting for ISBCS. A positive correlation was identified between opting for ISBCS and convenience to the patient $(r=0.76, p<0.01)$ and family/ carer/partner $(r=0.71, p<0.01)$ and wanting to limit numbers of hospital visits $(r=0.57, p<0.01)$. Fifty per cent agreed/strongly agreed that they were worried about the risk of simultaneous bilateral ocular complications, with this correlating with being less likely to opt for ISBCS $(r=-0.49, \mathrm{p}<0.01)$ and being scared of ISBCS $(r=0.67$, $p<0.01$ ). During COVID-19 lockdown, patients were less likely to want to minimise the time taken off work $(p<0.05)$ and less intolerant of a prolonged hospital visit $(p<0.05)$. Only $23 \%$ of respondents agreed/strongly agreed that they had familiarity with ISBCS.

Conclusions ISBCS was acceptable to $45 \%$ of our sampled population, suggesting limited routine implementation in the NHS is possible. Convenience and reduction in hospital visits appeared to contribute to this acceptance. Half of the patients expressed concern regarding bilateral complications and such concerns need addressing. Some attitudes did appear to change during the COVID-19 lockdown period. The familiarity of the concept of ISBCS is low suggesting the need for patient education.

\section{INTRODUCTION}

Modern cataract surgery (CS) typically offers excellent visual/refractive results, quality of life (QOL) improvements and few complications. ${ }^{12}$ It is one of the the most common

\section{Key messages}

What is already known about this subject?

Surgeon opinions with regards to immediate sequential bilateral cataract surgery (ISBCS) have been published, but there is no information regarding patient attitudes/concerns.

- To address this discrepancy, we conducted this study.

\section{What are the new findings?}

- Our survey suggested that $45 \%$ of our cataract surgery waiting list patients would be open to choosing ISBCS.

- This was found to be related to patient and family convenience and reducing additional hospital visits.

\section{How might these results change the focus of} research or clinical practice?

ISBCS allows for the provision of cataract surgery while limiting hospital attendances and thereby reducing COVID-19 contagion risks to both patients and medical personnel alike.

ISBCS is therefore being considered as part of a logistical and economic solution to the anticipated challenges faced by stretched cataract services in the post-COVID-19 era.

- Our data suggest that limited routine implementation of ISBCS in the National Health Service is possible.

surgical interventions, with in 2015, over a million conducted in the USA, 350000 in the UK and 20 million worldwide. ${ }^{3}{ }^{4}$ With increasing population growth/age, cataractassociated disease rates and patient/surgeon expectations, the CS demand is increasing. ${ }^{5}$ With economic and resource constraints, exacerbated by COVID-19 lockdown measures with limitations on elective surgery, this cataract burden is problematic and will require improvements in surgical productivity. 
Patients with bilateral cataracts, who have surgery in both rather than one eye, experience enhanced visual/ QOL improvements. ${ }^{6}$ Traditionally, surgery is performed on one eye at a time to prevent possible bilateral, sightthreatening events such as endophthalmitis, ${ }^{78}$ and less serious problems such as refractive surprise. ${ }^{9}$ However, delayed sequential bilateral CS (DSBCS) necessitates patients to attend additional appointments. Recently, there has been the promotion of immediately sequential bilateral CS (ISBCS) as a safe procedure. ${ }^{10}$ In 95 606 ISBCS patients, no cases of bilateral endophthalmitis were reported with routine intracameral antibiotic usage. ${ }^{11}$ Similarly, refractive surprise can be reduced by the exclusion of patients with risk factors, ${ }^{12}$ management of the preoperative ocular surface disease ${ }^{13}$ and usage of optical biometry/new intraocular lens calculation formulae. ${ }^{14}$

Compared with DSBCS, ISBCS has been shown to be cost-effective for hospitals ${ }^{15}$ and patient expenditure. ${ }^{1617}$ By reducing patient operating room (OR) transfer times and OR preparation times, ISBCS has the potential to increase efficiency, allowing more CS cases to undergo surgery within a given time. ${ }^{18}$

Surgeon opinions with regards to ISBCS have been published,${ }^{19-21}$ but there is no information regarding patient attitudes/concerns. To address this discrepancy, we designed this study. A questionnaire relating to patient attitudes/concerns with regards to ISBCS was developed. Patients presenting to the cataract service at our institution were invited to complete it, prior to and during COVID-19 lockdown.

\section{METHODS}

An anonymised questionnaire of 13 questions was designed. The first 10 were intended to determine: if cataracts were affecting vision bilaterally; patients' familiarity with ISBCS; convenience of ISBCS to patients and their carer/partner/family; agreement to undergo ISBCS if given the choice; desire to minimise hospital visits; wish to minimise time off work; levels of fear regarding ISBCS; concerns regarding possible bilateral complications and dislike of longer hospital visit on the day of surgery to undergo ISBCS. Questions were scored using a Likert scale from 1 to 5. Questions 11-13 were related to patient demographics including age range, gender and presence/absence of ophthalmic history. The survey was approved by our institution's audit and quality improvement project team. Data collection adhered to the tenets of the Declaration of Helsinki and the UK Data Protection Act.

Inclusion criteria comprised the presence of at least one cataract requiring surgical intervention, age over 18 years and ability to understand and complete the questionnaire. All questionnaires were undertaken under the supervision of an ophthalmologist knowledgeable in CS.

The study commenced in January 2020, prior to the COVID-19 lockdown in the UK, when patients were asked to participate at their preoperative outpatient appointment. Participation was offered to both first and second eye CS patients. During the COVID-19 lockdown when routine CS appointments were cancelled, patients on the CS waiting list at our institution, who had not completed the survey, were offered an opportunity to answer the questions remotely by telephone. Informed verbal consent was obtained in all cases.

\section{STATISTICAL ANALYSIS}

Data were analysed using SPSS V. 26.0 (IBM Corp). Frequency tables were used to show the proportion of responses for each question. The responses on the 5-point Likert scale were treated as non-parametric data. The Spearman rank correlation test was used to compare overall patient responses between questions 1 and 10 . The Mann-Whitney test was used to compare differences in response rate in relation to gender, between patients waiting for first and second eye surgery, and between patients with/without any self-reported ophthalmic history. The Kruskal-Wallis test was used to compare response rates in relation to age considering the four agegroup cohorts used in the study. Statistical significance was set at $\mathrm{p}<0.05$.

\section{RESULTS}

A total of 68 questionnaires were completed 'face to face' from 29 January to 14 March 2020. During the COVID-19 lockdown, from 7 to 29 May 2020, 199 questionnaires were completed remotely by telephone.

Most of the 267 respondents were female individuals $(61 \%)$ (table 1) with men being less scared by the notion

\begin{tabular}{|c|c|c|}
\hline & Frequency & Percentage (\%) \\
\hline \multicolumn{3}{|l|}{ Age (years) } \\
\hline $41-60$ & 48 & 18 \\
\hline $61-70$ & 83 & 31.1 \\
\hline $71+$ & 136 & 50.9 \\
\hline Total & 267 & 100 \\
\hline \multicolumn{3}{|l|}{ Gender } \\
\hline Male & 103 & 38.6 \\
\hline Female & 160 & 59.9 \\
\hline Not stated & 4 & 1.5 \\
\hline Total & 267 & 100 \\
\hline \multicolumn{3}{|c|}{ Ophthalmic history } \\
\hline Yes & 79 & 29.6 \\
\hline No & 188 & 70.4 \\
\hline Total & 267 & 100 \\
\hline \multicolumn{3}{|c|}{ Pseudophakia } \\
\hline Yes & 128 & 47.9 \\
\hline No & 139 & 52.1 \\
\hline Total & 267 & 100 \\
\hline
\end{tabular}


of ISBCS $(\mathrm{p}<0.05)$. The remaining questions pertaining to ISBCS showed no significant differences between genders.

Half of the respondents were aged 71 years or over $(51 \%)$ (table 1). The older age group was less likely to report being scared compared with younger groups $(p<0.05)$ and less likely to need to minimise the time taken off work $(p<0.05)$. The remaining questions pertaining to ISBCS showed no differences between age groups.

Previous CS in one eye was documented in $48 \%$, and $30 \%$ reported previous ophthalmic problems (table 1 ). No differences were found with regards to the questions pertaining to ISBCS when data were analysed based on pseudophakic status or past ophthalmic history. Fiftythree per cent of patients who already had CS on one eye agreed/strongly agreed that they would opt for ISBCS if they had been given the choice.

Prior to the COVID-19 lockdown, patients were more likely to be visually symptomatic with cataracts $(p<0.05)$ and more familiar with ISBCS $(\mathrm{p}<0.05)$. During the lockdown, patients were less concerned about minimising the time taken off work $(p<0.05)$ and less intolerant of a prolonged hospital visit $(\mathrm{p}<0.05)$.

$53 \%$ of respondents agreed/strongly agreed that cataract was affecting vision in both eyes, $53 \%$ of whom agreed/strongly agreed with opting for ISBCS (table 2). There was no correlation between how symptomatic patients were from cataracts and previous CS.

Forty-eight per cent agreed/strongly agreed that ISCBCS would be convenient for them, and $46 \%$ for their family/carer/partner, with both responses having a strong positive correlation $(r=0.79, \mathrm{p}<0.01)$ (table 2$)$.

Forty-five per cent of respondents agreed/strongly agreed with opting for ISBCS if given the option (table 2), with a positive correlation between this and convenience to the patient $(r=0.76, \mathrm{p}<0.01)$ and their family/carer/ partner $(r=0.71, \mathrm{p}<0.01)$. There was a positive correlation between the choice of opting for ISBCS and wanting to limit hospital visits $(r=0.57, \mathrm{p}<0.01)$. Those who reported being scared were less likely to opt for ISBCS $(r=-0.51$, $\mathrm{p}<0.01)$, as was the case for those worried about the risk of bilateral simultaneous ocular complications $(r=-0.49$, $\mathrm{p}<0.01)$.

Only 23\% agreed/strongly agreed that they had any familiarity with the concept of ISBCS (table 2), with no strong correlations between this factor and the other ISBCS questions.

Sixty-four per cent agreed/strongly agreed that they wanted to minimise hospital visits for CS to both eyes, which was strongly correlated with opting for ISBCS $(r=0.57, \mathrm{p}<0.01)$ and to a lesser extent with self $(r=0.46$, $\mathrm{p}<0.01)$ and family convenience $(r=0.48, \quad \mathrm{p}<0.01)$ (table 2).

Only of $29 \%$ of respondents agreed/strongly agreed that they wanted to minimise the time taken off work with $43 \%$ remaining neutral on the matter.
Table 2 Responses (numbers and percentages) to questions pertaining to ISBCS

\begin{tabular}{|c|c|}
\hline Question & n (\%) \\
\hline \multicolumn{2}{|c|}{$\begin{array}{l}\text { 1.My cataracts affect the vision in both my } \\
\text { eyes. }\end{array}$} \\
\hline Strongly agree & $72(27)$ \\
\hline Agree & $68(25.5)$ \\
\hline Neutral & $23(8.6)$ \\
\hline Disagree & $28(10.5)$ \\
\hline Strongly disagree & $76(28.5)$ \\
\hline \multicolumn{2}{|c|}{$\begin{array}{l}\text { 2.I am familiar with the concept of cataract } \\
\text { surgery for both eyes in the same sitting. }\end{array}$} \\
\hline Strongly agree & $21(7.9)$ \\
\hline Agree & 39 (14.6) \\
\hline Neutral & $14(5.2)$ \\
\hline Disagree & $33(12.4)$ \\
\hline Strongly disagree & $160(59.9)$ \\
\hline \multicolumn{2}{|c|}{$\begin{array}{l}\text { 3. Cataract surgery for both my eyes in the } \\
\text { same setting would be convenient for me. }\end{array}$} \\
\hline Strongly agree & $81(30.3)$ \\
\hline Agree & $48(18)$ \\
\hline Neutral & $36(13.5)$ \\
\hline Disagree & $41(15.4)$ \\
\hline Strongly disagree & $61(22.8)$ \\
\hline
\end{tabular}

4.Cataract surgery for both my eyes in the same setting would be convenient for my family/carer/partner.

$\begin{array}{ll}\text { Strongly agree } & 68(25.5) \\ \text { Agree } & 55(20.6) \\ \text { Neutral } & 56(21) \\ \text { Disagree } & 33(12.4) \\ \text { Strongly disagree } & 55(20.6)\end{array}$

5.I would request cataract surgery to be done for both my eyes in the same sitting if I had the choice.

$\begin{array}{ll}\text { Strongly agree } & 75(28.1) \\ \text { Agree } & 45(16.9) \\ \text { Neutral } & 20(7.5) \\ \text { Disagree } & 28(10.5) \\ \text { Strongly disagree } & 99(37.1)\end{array}$

6.I would like to minimise the number of hospital visits it takes for both my cataracts to be removed.

Strongly agree

$92(34.5)$

Agree $78(29.2)$

Neutral $40(15)$

Disagree

$23(8.6)$

Strongly disagree

$34(12.7)$ 


\begin{tabular}{|c|c|}
\hline Question & $n(\%)$ \\
\hline \multicolumn{2}{|c|}{$\begin{array}{l}7 . I \text { would like to minimise the time I need to } \\
\text { take off work for both my cataracts to be } \\
\text { removed. }\end{array}$} \\
\hline Strongly agree & $46(17.2)$ \\
\hline Agree & 31 (11.6) \\
\hline Neutral & $116(43.4)$ \\
\hline Disagree & $23(8.6)$ \\
\hline Strongly disagree & 51 (19.1) \\
\hline \multicolumn{2}{|c|}{$\begin{array}{l}8 . I \text { am scared by the idea of cataract surgery } \\
\text { being done for both my eyes in the same } \\
\text { sitting. }\end{array}$} \\
\hline Strongly agree & $61(22.8)$ \\
\hline Agree & $64(24)$ \\
\hline Neutral & 29 (10.9) \\
\hline Disagree & 60 (22.5) \\
\hline Strongly disagree & 53 (19.9) \\
\hline \multicolumn{2}{|c|}{$\begin{array}{l}9.1 \text { am worried about the risk of complication } \\
\text { to both eyes at once if cataract surgery is } \\
\text { done for both my eyes in the same sitting. }\end{array}$} \\
\hline Strongly agree & $69(25.8)$ \\
\hline Agree & 65 (24.3) \\
\hline Neutral & 37 (13.9) \\
\hline Disagree & 54 (20.2) \\
\hline Strongly disagree & 42 (15.7) \\
\hline \multicolumn{2}{|c|}{$\begin{array}{l}10 . I \text { dislike that cataract surgery for both my } \\
\text { eyes in the same sitting would mean a longer } \\
\text { hospital visit on the day. }\end{array}$} \\
\hline Strongly agree & $16(6)$ \\
\hline Agree & 36 (13.5) \\
\hline Neutral & 34 (12.7) \\
\hline Disagree & 53 (19.9) \\
\hline Strongly disagree & $128(47.9)$ \\
\hline
\end{tabular}

ISBCS, immediate sequential bilateral cataract surgery.

Forty-seven per cent of respondents agreed/strongly agreed that they were scared by the idea of ISBCS, which was strongly correlated to being less likely to opt for ISBCS if given the choice $(r=-0.51, \mathrm{p}<0.01)$ and being less likely to find ISBCS convenient for themselves $(r=-0.57, \mathrm{p}<0.01) \quad$ (table 2). Half of the respondents agreed/strongly agreed that they were worried about the risk of simultaneous bilateral ocular complications, with a strong correlation between this concern and being less likely to opt for ISBCS $(r=-0.49, \mathrm{p}<0.01)$ and being scared of ISBCS $(r=0.67, \mathrm{p}<0.01)$.

Only $20 \%$ of respondents agreed/strongly agreed with the notion that a longer hospital visit on the day to have CS on both eyes in the same sitting would be undesirable (table 2).

\section{DISCUSSION}

ISBCS offers benefits of convenience and cost-efficiency for patients, by reducing attendance at clinics/hospitals and postoperative recovery time. ${ }^{16}{ }^{17}$ Similarly, it allows convenience and cost-efficiency to hospitals by decreasing patient visits ${ }^{15}$ and potentially improving OR productivity. ${ }^{18}$ With modern aseptic techniques and intracameral antibiotics, rare bilateral sight-threatening complications are very unlikely, ${ }^{11}$ whereas with modern biometric methodologies and careful preoperative patient selection and management, other complications are uncommon. ${ }^{12-14}$ During the current COVID-19 pandemic, it would be hoped that the adoption of ISBCS would allow the provision of CS while limiting hospital attendances, thereby reducing COVID-19 contagion risks for both patients and medical personnel alike. For these reasons in the UK and globally, the introduction of more routine ISBCS into CS management pathways is under consideration. ${ }^{22}$ Clearly, when introducing such new pathways, it is essential to fully engage medical personnel to ensure safety and efficacy. However, it is also vital to gauge patient opinion and acceptance. For this reason, we undertook this survey to elucidate patient attitudes/ concerns with regard to ISBCS.

Most respondents were female individuals, which might be expected given that several studies have reported the cataract burden, possibly because of older age and reduced socioeconomic status, is increased in women. ${ }^{23}$ How this gender disparity might have influenced our results is undetermined, but male respondents were less likely to fear ISBCS. Increased fear of CS in women compared with men has been reported, with the experience of a good operative outcome in the first eye reducing fear of surgery on the second. ${ }^{24}$ This suggests that gender differences concerning fear of ISBCS might be expected and need to be taken into consideration with a wider ISBCS introduction.

Most respondents were aged 71 years or over, which is expected given the association of cataract with increasing age. ${ }^{25}$ Older patient groups were less likely to report being scared compared with younger groups, perhaps reflecting a greater degree of stoicism and possible acceptance of new medical interventions that warrant further investigation. Older patient age groups were less likely to need to minimise the time taken off work, conceivably reflecting that they were retired and not employed.

Almost half of the respondents had previously undergone CS in one eye and interestingly of these, 53\% agreed/strongly agreed that they would opt for ISBCS if they had been given the choice, compared with $42 \%$ who had not yet undergone CS. This suggests that, as found in previous studies,${ }^{24}$ the experience of a good outcome for CS in the first eye reduces fear of further ocular surgery, although differences in fear of ISBCS were not evident between pseudophakic and non-pseudophakic groups. However, it does indicate that approximately $50 \%$ of patients currently listed for DSBCS would prefer ISBCS and would opt for it given the choice by their surgeons. 
Almost one-third reported previous ophthalmic problems. This might be expected given most were over the age of 71. Although not part of this survey, these problems were mainly pertaining to glaucoma and medical retina, which given the age ranges of our patients is expected. Having previous ophthalmic problems did not appear to influence attitudes towards ISBCS, suggesting that this is not an important factor when considering patient acceptance of ISBCS.

Just over half of the respondents agreed/strongly agreed that cataract was affecting the vision on both eyes, $53 \%$ of whom agreed/strongly agreed that they would opt for ISBCS (table 2). Interestingly, there was no difference between the degree of reported visual symptomology between patients with cataracts in both eyes and those who had previous CS in one eye, perhaps highlighting the known benefits of second eye surgery on QOL. ${ }^{6}$

For patients themselves and their family/carer/ partner, just under half agreed/strongly agreed that they professed ISBCS as being convenient (table 2). As expected, perceived convenience for patients and family/ carer/partners were strongly correlated. Perceived convenience was also strongly correlated to agreeing/strongly agreeing to opt for ISBCS if given a choice, suggesting that this is an important factor that patients consider for the adoption of ISBCS. No significant differences were noted in response to questions of convenience for family/ carer/partners across different age groups, suggesting that it is not only the very elderly who rely on friends and family to access their hospital eye services and help them during their postoperative recovery.

Just under half of the respondents (45\%) agreed/ strongly agreed with opting for ISBCS if given the option (table 2). This was positively correlated to questions concerning convenience and limiting hospital visits. This quite high percentage is encouraging, suggesting the limited routine implementation of ISBCS in the National Health Service (NHS) is possible, with all its associated cost savings ${ }^{15-17}$ and potential for improving surgical productivity. ${ }^{18}$

Under a quarter agreed/strongly agreed that they had any familiarity with the concept of ISBCS (table 2). Although, there were no strong correlations between this factor and the other ISBCS questions, given the reported lack of knowledge of ISBCS, patient education in this area is required and further studies needed to see if by informing patients of the nature of ISBCS and the very small risk of bilateral sight-threatening complications, acceptance well above $50 \%$ can be achieved.

Almost two-thirds (64\%) wanted to minimise their number of hospital visits for having both cataracts removed, which was strongly correlated with opting for ISBCS and to the patient and family convenience. This desire to reduce hospital/clinic visits appears to be a principal factor for patients in deciding whether to choose ISBCS or not. It is also an important factor in the cost reduction for ISBCS for patients and hospital services ${ }^{15-17}$ and during the current COVID-19 pandemic limitation of such face-to-face hospital/clinic visits, it is perceived as beneficial to minimise contagion risks for patients and medical personnel alike.

Only $29 \%$ agreed/strongly agreed that they wanted to minimise the time taken off work with $43 \%$ remaining neutral on the matter (table 2). This is surprising given that minimising time off work is an important factor in the cost-effectiveness of ISBCS. ${ }^{16}{ }^{17}$ The economic cost of cataract accounts for as much as $20 \%$ of healthcare system costs in the UK, with lower productivity from lower workforce participation and absenteeism contributing to this figure. ${ }^{26}$ However, given the age of our CS population, most of whom are likely to be retired and not in employment, this low figure might be expected. It is also likely to be confounded by the fact that although some patients completed the survey prior to lockdown measures, the majority (almost $75 \%$ ) completed it remotely by telephone when the lockdown was in place and at this time a lot of the working population were not in work/could not work, thus potentially influencing results pertaining to this question.

Almost half (47\%) of the respondents agreed/strongly agreed that they were scared by the idea of ISBCS, which was strongly correlated to being less likely to opt for ISBCS if given the choice, finding ISBCS to be less convenient for themselves and most strongly with concerns about the risks of bilateral ocular complications. Indeed, half of the patients surveyed were concerned about bilateral complications (table 2). It appears that such worries are important barriers to patient acceptance of ISBCS. Fear of the unknown is a rational response and patient familiarity with ISBCS was, from our survey, limited. It might be hoped that patient education might lessen this factor. The risk of simultaneous bilateral complication is a valid fear, but reported bilateral sight-threatening complications with modern surgical approaches are very rare events, with one report finding only four cases over a 60-year period, each with identified breaches to the standard infection control protocol. ${ }^{11}$ Thus, patient education, with continued vigilance and strict adherence to aseptic protocols, is mandatory to help lessen such concerns. It is of note that the notion that a longer hospital visit on the day to have surgery on both eyes in the same sitting did not appear to be a significant barrier to ISBCS acceptance with only a fifth of patients seeing it as a concern (table 2)

This survey was commenced in January 2020. Unfortunately, it was interrupted by the COVID-19 pandemic becoming evident in the UK. Prior to the pandemic, the patients completed the survey face to face. After lockdown measures were introduced, this was not possible and we conducted the survey remotely by telephone. Although this is not ideal and has to be taken into consideration when interpreting some of our results, it also provided a very unique opportunity to gauge how some opinions might be altered by the lockdown measures and the COVID-19 pandemic. It is of interest that in the lockdown period, patients were less likely to report their 
cataracts as symptomatic. This may relate to the coronavirus pandemic serving as a distraction away from their other health needs. Certainly, there has been concern reported in the media of patients not accessing healthcare services in the UK, for potentially life-threatening medical conditions such as cancer. ${ }^{27}$ In addition, in the lockdown, patients were less likely to report a need to minimise the time off work and were less intolerant of a longer hospital visit on the day, which might reflect a change due to many individuals working from home and many on 'furlough'. Interestingly, there was not a significant difference in responses to the question of minimising hospital visits when comparing prelockdown and postlockdown responses $(\mathrm{p}=0.86)$, as we might have expected a difference, based on possible fears concerning contracting COVID-19 travelling to, from and during hospital appointments.

Our results indicate that ISBCS was acceptable to $45 \%$ of our sampled population, suggesting that the limited routine implementation of ISBCS in the NHS is possible. This is important, as ISBCS is being considered as part of the logistical and economic solution to the anticipated challenges faced by stretched CS services in the postCOVID-19 era. Convenience to patients and their carers/ family/relatives and reduction in the number of hospital visits appeared to be important factors contributing to this acceptance. Half of the patients expressed concern regarding bilateral complications, which was strongly correlated with fear of ISBCS. Such concerns need addressing and might be addressed by patient education with regards to the rarity of such events. The familiarity of the concept of ISBCS is low, highlighting the need for patient education. Some attitudes did appear to change during the COVID-19 lockdown period, which requires further elucidation.

Contributors VS, DO'B, KN and SL conceptualised project. VS, KN, LM, AJ, DP, JG, $\mathrm{SH}, \mathrm{EA}, \mathrm{SV}$ and SL contributed to data collection. VS performed data analysis and produced first draft of manuscript. DO'B revised several iterations. Final manuscript reviewed and approved by all coauthors.

Funding The authors have not declared a specific grant for this research from any funding agency in the public, commercial or not-for-profit sectors.

Competing interests DO'B holds non-commercial research grants with Rayner Ltd and Avedro. He has undertaken consultancy work for Avedro, Sparca and Alcon in the past 12 months. He holds stock in Sparca.

Patient and public involvement Patients and/or the public were not involved in the design, or conduct, or reporting, or dissemination plans of this research.

Patient consent for publication Not required.

Provenance and peer review Not commissioned; externally peer reviewed.

Data availability statement All data relevant to the study are included in the article.

Open access This is an open access article distributed in accordance with the Creative Commons Attribution Non Commercial (CC BY-NC 4.0) license, which permits others to distribute, remix, adapt, build upon this work non-commercially, and license their derivative works on different terms, provided the original work is properly cited, appropriate credit is given, any changes made indicated, and the use is non-commercial. See: http://creativecommons.org/licenses/by-nc/4.0/.
Darshak S Patel http://orcid.org/0000-0002-4583-5605

\section{REFERENCES}

1 Day AC, Donachie PH, Sparrow JM, et al. Royal College of Ophthalmologists' National Ophthalmology Database. The Royal College of Ophthalmologists' National Ophthalmology Database study of cataract surgery: report 1, visual outcomes and complications. Eye 2015;29:552-60.

2 Lamoureux EL, Fenwick E, Pesudovs K, et al. The impact of cataract surgery on quality of life. Curr Opin Ophthalmol 2011;22:19-27.

3 KUOPAMN S. The global intraocular lens market is forecast to reach \$3.1billion [Online]. ASD Reports 2015.

4 The Royal College of Ophthalmologists. The way forward cataract report, 2015. Available: www.rcophth.ac.uk/standards-publicationsresearch/the-way-forward

5 Minassian DC, Reidy A. Future sight loss UK (2): an epidemiological and economic model for sight loss in the decade 2010-2020, 2009. Available: http://www. rnib. org. uk/ sites/ default/ files/ FSUK_2.pdf

6 Laidlaw DA, Harrad RA, Hopper CD, et al. Randomised trial of effectiveness of second eye cataract surgery. Lancet 1998;352:925-9.

7 Ozdek SC, Onaran Z, Gürelik G, et al. Bilateral endophthalmitis after simultaneous bilateral cataract surgery. J Cataract Refract Surg 2005;31:1261-2.

8 Kashkouli MB, Salimi S, Aghaee H, et al. Bilateral Pseudomonas aeruginosa endophthalmitis following bilateral simultaneous cataract surgery. Indian J Ophthalmol 2007:55:374-5.

9 Olsen T. Use of fellow eye data in the calculation of intraocular lens power for the second eye. Ophthalmology 2011;118:1710-5.

10 Arshinoff SA, Strube YNJ, Yagev R. Simultaneous bilateral cataract surgery. J Cataract Refract Surg 2003;29:1281-91.

11 Arshinoff SA, Bastianelli PA. Incidence of postoperative endophthalmitis after immediate sequential bilateral cataract surgery. $J$ Cataract Refract Surg 2011;37:2105-14.

12 Lundström M, Dickman M, Henry Y, et al. Risk factors for refractive error after cataract surgery: Analysis of 282811 cataract extractions reported to the European Registry of Quality Outcomes for cataract and refractive surgery. J Cataract Refract Surg 2018;44:447-52.

13 Ho VWM, Stanojcic N, O'Brart NAL, et al. Refractive surprise after routine cataract surgery with multifocal IOLs attributable to corneal epithelial basement membrane dystrophy. J Cataract Refract Surg 2019;45:685-9.

14 Roberts TV, Hodge C, Sutton G, et al. Contributors to the vision eye Institute IOL outcomes registry. Comparison of Hill-radial basis function, Barrett universal and current third generation formulas for the calculation of intraocular lens power during cataract surgery. Clin Exp Ophthalmol 2018;46:240-6.

15 O'Brien JJ, Gonder J, Botz C, et al. Immediately sequential bilateral cataract surgery versus delayed sequential bilateral cataract surgery: potential hospital cost savings. Can J Ophthalmol 2010;45:596-601.

16 Leivo T, Sarikkola A-U, Uusitalo RJ, et al. Simultaneous bilateral cataract surgery: economic analysis; Helsinki simultaneous bilateral cataract surgery study report 2. J Cataract Refract Surg 2011;37:1003-8.

17 Rush SW, Gerald AE, Smith JC, et al. Prospective analysis of outcomes and economic factors of same-day bilateral cataract surgery in the United States. J Cataract Refract Surg 2015;41:732-9.

18 O'Brart DP, Roberts H, Naderi K, et al. Economic modelling of immediately sequential bilateral cataract surgery (ISBCS) in the National health service based on possible improvements in surgical efficiency. BMJ Open Ophthalmol 2020;5:e000426.

19 Amsden LB, Shorstein NH, Fevrier H, et al. Immediate sequential bilateral cataract surgery: surgeon preferences and concerns. Can $J$ Ophthalmol 2018;53:337-41.

20 Mills EC, Zarei-Ghanavati M, Liu CSC. Immediate sequential bilateral cataract surgery: the rationale, implementation, and beliefs of ophthalmic surgeons across Europe. J Cataract Refract Surg 2019;45:1725-31.

21 Lee $\mathrm{E}$, Balasingam B, Mills EC, et al. A survey exploring ophthalmologists' attitudes and beliefs in performing immediately sequential bilateral cataract surgery in the United Kingdom. BMC Ophthalmol 2020;20:210.

22 RCOphth Webinar. Immediate simultaneous bilateral cataract surgery, 2020. Available: www.rcophth.ac.uk/2020/06/new-webinarimmediate-sequential-bilateral-cataract-surgery-isbcs

23 Lou L, Ye X, Xu P, et al. Association of sex with the global burden of cataract. JAMA Ophthalmol 2018;136:116-21.

24 Fagerström R. Fear of a cataract operation in aged persons. Psychol Rep 1993;72:1339-46. 
25 Asbell PA, Dualan I, Mindel J, et al. Age-Related cataract. Lancet 2005;365:599-609.

26 Pezzullo L, Streatfeild J, Simkiss P, et al. The economic impact of sight loss and blindness in the UK adult population. BMC Health Serv Res 2018;18:63.
27 Bodkin H. Covid-19's 'devastating' impact on cancer services. The Telegraph, 2020. Available: www.telegraph.co.uk/news/2020/06/11/ covid-19s-devastating-impact-cancer-services 